\begin{tabular}{|c|c|c|}
\hline $\begin{array}{l}\text { Research Process } \\
\text { Components }\end{array}$ & Challenges & Opportunities \\
\hline $\begin{array}{l}\text { Identifying knowledge } \\
\text { gaps }\end{array}$ & $\begin{array}{l}\text { Understanding what is already known and identifying gaps } \\
\text { in important knowledge from a generalist perspective and } \\
\text { relevant to the health of people, families, communities, and } \\
\text { health care in a family medicine setting }\end{array}$ & $\begin{array}{l}\text { Making known the tremendous complementarities } \\
\text { between the NIH roadmap and the family } \\
\text { medicine research approach }\end{array}$ \\
\hline Hypothesis generation & Posing and focusing the right questions & $\begin{array}{l}\text { Engaging clinicians and communities in networks } \\
\text { and participatory approaches }\end{array}$ \\
\hline Acquiring funding & $\begin{array}{l}\text { Lack of funding for primary care, noncategorical, research; } \\
\text { study sections unfamiliar with practice-based, community } \\
\text { participatory and integrative research }\end{array}$ & $\begin{array}{l}\text { Billionizing AHRQ; advocating for participation in } \\
\text { review and leadership roles; promoting PBRNs; } \\
\text { supporting Grant Generating Project }\end{array}$ \\
\hline $\begin{array}{l}\text { Creating and maintaining } \\
\text { research laboratories }\end{array}$ & $\begin{array}{l}\text { Supply of family medicine investigators with research skills } \\
\text { and committed time; creation of family medicine patient } \\
\text { cohorts }\end{array}$ & $\begin{array}{l}\text { Developing PBRN capacity; research centers for } \\
\text { primary care health }\end{array}$ \\
\hline Executing studies & $\begin{array}{l}\text { Competing clinical demands with inadequate infrastructure } \\
\text { and funding; research coordination across dispersed sites; } \\
\text { IRB challenges; HIPAA }\end{array}$ & $\begin{array}{l}\text { Lobbying for funding; helping AHRQ advocate for } \\
\text { central PBRN IRB and HIPAA authorization }\end{array}$ \\
\hline Analyzing data & $\begin{array}{l}\text { Sophistication of family medicine investigators in data analysis } \\
\text { and qualitative research methods }\end{array}$ & $\begin{array}{l}\text { Research centers for primary care health; practice- } \\
\text { and community-based research, and dissemination } \\
\text { networks }\end{array}$ \\
\hline Dissemination & $\begin{array}{l}\text { Scarcity of scientific meetings for primary care research; } \\
\text { underdeveloped mechanisms for engaging patients, } \\
\text { communities, clinicians, and policymakers in knowledge } \\
\text { generation and use }\end{array}$ & $\begin{array}{l}\text { Practice- and community-based research and } \\
\text { dissemination networks; advancing support of } \\
\text { Annals; support of mentoring projects }\end{array}$ \\
\hline Implementation & $\begin{array}{l}\text { Doing research in the setting (and from the perspective) in } \\
\text { which findings will be applied to reduce the problem of } \\
\text { translation into practice }\end{array}$ & PBRNs; EHRs \\
\hline $\begin{array}{l}\text { Identifying knowledge } \\
\text { gaps }\end{array}$ & $\begin{array}{l}\text { The cycle starts again. (There are other iterative loops } \\
\text { within the cycle). }\end{array}$ & $\begin{array}{l}\text { Work toward a culture of inquiry throughout family } \\
\text { medicine }\end{array}$ \\
\hline
\end{tabular}

The research process, as outlined in Table 1, provides a helpful perspective for planning actions to enhance the science base of family medicine. The steps of the research process, like the FFM plan, are highly interrelated, and require a team process and individual initiative and leadership.

In addition, the task force is pleased to report that the American Academy of Family Physicians is now actively supporting the adoption of the International Classification of Primary Care (ICPC) as a primary care-relevant information terminology standard for electronic health records. The AAFP decision is a welcome development that will help NAPCRG in its longterm commitment to advancing the ICPC. In addition, the task force plans to work with AHRQ to advocate for and develop a national human subjects protection and HIPAA authorization board for practice-based research networks. If you are interested in participating or learning more about the work of the task force, contact Stacy Brungardt, CAE, NAPCRG executive director, at napcrg@stfm.org.

Frederick Chen, MD, MPH Stacy Brungardt, CAE

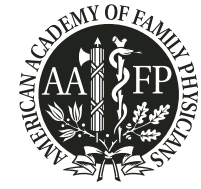

From the American Academy of Family Physicians

Ann Fam Med 2004;2:615-617. DOI: 10.1370/afm.253.

\section{METRIC: NEW AAFP PERFORMANCE MEASUREMENT PROGRAM WILL MEET MULTIPLE GOALS}

Attendees at the American Academy of Family Physicians Scientific Assembly in October got a sneak preview of a new AAFP program: METRIC-Measuring, Evaluating and Translating Research Into Care. The program will launch in 2005.

Designed to fulfill the criteria for Part IV of the American Board of Family Practice Maintenance of Certification Program for Family Physicians, or MC-FP, METRIC also will provide physicians CME credit for completing practice-based performance measurement projects.

But Bruce Bagley, MD, AAFP Medical Director of Quality Improvement, hopes the program will have more lasting effects.

"We see it as a way to get family physicians interested in doing quality improvement work in their prac- 
tices," Bagley explains. "METRIC is really a 'low hurdle' in terms of the amount of work that the physician will have to do. Our hope is that we can teach family physicians how to do these kinds of interventions on an ongoing basis."

According to the ABFP, each Diplomate is required to complete 1 "Performance in Practice Module" during the 7 -year recertification cycle. This part of the MCFP process harkens back to the office record review requirement $\mathrm{ABFP}$ Diplomates previously were required to complete. Rather than focusing simply on recordkeeping practices, however, the new process will focus on improving practice performance and, ultimately, patient outcomes.

\section{Hands-On Demo}

Participants at the AAFP meeting previewed an abbreviated version of METRIC's diabetes module, the first of 2 modules developed for the program. The diabetes module is scheduled to launch in January; a module on coronary artery disease will go live in July. The plan is to continue to launch 2 modules each year, with each module being accessed through the Academy's Web site.

The demo at the Scientific Assembly served 2 purposes, says Christine Pullman, manager of the AAFP METRIC program. First, it gave family physicians attending the meeting a chance to test-drive the new online program before it launches next year. Second, it allowed interested individuals to sign up to perform beta testing of the full diabetes module beginning in November. Those individuals will work through the program module and give input on it.

An added plus: Physicians beta-testing METRIC can earn free CME credit_-20 Prescribed credits-for completing the entire module. Although not finalized at press time, the expected cost for AAFP members to use one of the METRIC modules to complete their MC-FP Part IV requirement is $\$ 25$. Nonmember Diplomates will likely pay $\$ 50$.

In awarding CME credit for this activity, the Academy is moving down an educational path similar to that laid out in a recently completed AMA pilot project allowing physicians to earn Physician's Recognition Award Category 1 credit for performance improvement activities.

\section{Nuts and Bolts}

Here's how METRIC will work when it launches. Participants will first complete a brief practice assessment questionnaire online. The questionnaire is designed to gather information about the physician's practice environment. Is it a large multispecialty practice located in an academic institution or a smaller family medicine group — even a solo practice-located in a rural community? How many patients call the practice their medical home? Of those patients, how many are actively involved in their own care? Does the practice use a team approach to patient care? If so, how does that team function? What protocols and tools are used in the practice to track patients' clinical outcomes?

On completion of the practice assessment, the physician will be asked to select 10 patient records from his or her practice based on specific diagnostic codes. The physician will enter data on various clinical and practice performance measures from each of those records into a Web-based data abstraction tool.

After the data abstraction component is completed, participants will receive immediate feedback on how their practice assessment responses compared with those of their family medicine peers. They can also view their baseline performance measurement data. By clicking on each measure, physicians can access relevant evidence-based guidelines.

Based on participants' selection of practice assessment areas and performance measures needing improvement, the program will suggest interventions shown to affect clinical outcomes and will provide tools to facilitate process improvement. METRIC participants will then develop individualized action plans using the interventions they've selected, along with appropriate tools and instructions on their use.

It's here that Bagley sees the program giving physicians a chance to see the value of using these interventions as part of their ongoing quality enhancement efforts.

"For instance, if an FP puts a registry system in place as one of the interventions chosen as part of his or her METRIC action plan, it is our hope that the physician will realize the value of that system and apply the same principles to registries for multiple chronic conditions," Bagley says.

Several months later, the METRIC program will send participants a reminder that it's time to remeasure. Physicians will again record data from 10 patient records on the same performance measures. Those follow-up data will then be displayed alongside their baseline data so participants can gauge how their performance has changed. In addition, both performance assessment report screens-baseline and follow-upallow physicians to instantly create graphs using their own data.

When the entire exercise is completed, the METRIC program will notify the ABFP that the physician has fulfilled his or her MC-FP Part IV requirement, and CME credit will be awarded. For AAFP members, that credit will automatically be added to their computerized CME records. 


\section{Program Support}

The overall METRIC program is supported by multiple educational grants. Specifically, the diabetes module was funded through an educational grant from Merck \& Co, Inc; the coronary artery disease module is being supported by Merck/Schering-Plough Pharmaceuticals. CECity.com, Inc, an award-winning online technology provider based in Pittsburgh, $\mathrm{Pa}$, developed the software supporting the METRIC modules.

A Physician Advisory Committee-composed of family physicians whose expertise spans various areas of clinical content, performance measurement, and quality improvement—will guide development of module objectives, performance measures, and interventions. Each of these components will be supported by evidence-based clinical content. Bagley chairs the advisory committee.

The topics will be drawn from several sources. Among them are the Institute of Medicine's list of the top 20 health conditions in the United States and the results of AAFP surveys on members' perceived CME needs. "So we're not going to have obscure diagnoses; we're going to have disease topics that are significant to the family physician and to the public," Pullman explains.

Launched modules will remain active for 3 years and will be periodically updated by the advisory committee. After that time, each module will be evaluated to determine whether it should be continued.

\section{Future Attractions}

Data submitted to the METRIC program represent a valuable resource, Pullman notes, and the program's developers plan to retain those data for use in future practice-based research. "Once the physician completes the program, the data would be kept in aggregate form-after having been completely disassociated from the physician's information," she says.

"This is a baby step," says Pullman, referring to METRIC in the context of full-fledged quality enhancement efforts. And yet programs such as METRIC are key to developing a sustainable culture of quality improvement, she adds.

"Keep in mind that the current requirement for MC-FP Part IV is to do 1 practice improvement project in every recertification cycle-that is, once every 7 years," Bagley emphasizes. "This would not be adequate to fulfill our goal of getting family physicians involved in ongoing quality improvement and office redesign efforts.

"The Academy's Quality Enhancement Program will also teach FPs the needed skills to implement the new model of care (described in the Future of Family Medicine report). Many of the interventions that we will recommend in the METRIC program will be the same as those recommended in QEP, so there is some synergy."

\author{
Cindy Borgmeyer \\ AAFP News Department
}

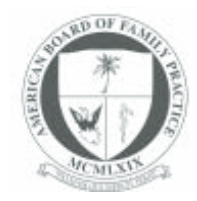

From the American

Board of Family Practice

Ann Fam Med 2004;2:617-618. DOI: 10.1370/afm.254.

\section{ABFP'S 2005 COMPUTER-BASED EXAMINATIONS}

The American Board of Family Practice (ABFP) will administer its certification/recertification and sports medicine examinations exclusively online in 2005. The certification/recertification examinations will require 1 day, and the sports medicine examination will require a half day. Each will be conveniently offered at more than 200 locations throughout the United States, Guam, and Puerto Rico. The number of examination dates has been increased to be offered on selected Thursdays, Fridays, and Saturdays. Expanded availability of dates and locations will help reduce the candidates' loss of income from practice, travel, and lodging expenses. The examinations will be offered on July 21, 22, 23, 28, 29, and 30, and on August 4, 5, or 6. Additionally, the examinations will be offered on December 2 and 3 with limited eligibility (off-cycle residents, candidates with extraordinary circumstances precluding them from taking the July/August examination, and candidates who are unsuccessful on the July/August examination.)

The conversion of the examination from paper and pencil to online has been approached with the candidate's ease of use in mind. The computer-based test has been designed to be used by those with minimal computer experience and typing skills. Unique tools have been developed that will allow individuals to duplicate the testing methods they used on the written examination. In addition to the electronic tools listed below, candidates will also be provided with an erasable white board and pen to make calculations and/or notes during the examination.

Some of the electronic tools include an item navigation toolbar; buttons indicating first, previous, next, and last test items; progress in the test displaying the number of answered questions and flagged questions; a flagging button to tag questions for review later; $a$ jump button to return quickly to items to review, flag to review, or change an answer; ability to enlarge graphics 